\title{
THE EFFECT OF DAMPING COEFFICIENTS ON THE TORSIONAL VIBRATION OF THE DAMPED MULTI-BRANCH GEARS SYSTEM
}

\author{
Jabbar Firouzi ${ }^{1}$, Hassan Ghassemi ${ }^{1}$, Karim Akbari Vakilabadi ${ }^{2}$, Hadi Khalilnezhad ${ }^{2}$ \\ ${ }^{I}$ Department of Maritime Engineering, Amirkabir University of Technology \\ Tehran, Iran \\ ${ }^{2}$ Department of Mechanic Engineering, Imam Khomeini University of Marine Science \\ \& Technology, Nowshahr, Iran \\ gasemi@aut.ac.ir
}

Received: 22 October 2017; Accepted: 29 December 2017

\begin{abstract}
The effect of the damping coefficients has been considered to estimate the torsional vibration of the multi-branch gears systems. In this paper, the effect of the viscous damping between the gears and the fluid in which the gear is working and the effect of the structural damping of the shafts in a three-branched gear system is investigated. Initially, the governing equations were derived and then the damping effects were studied using MATLAB code. In order to validate the results which prepared by MATLAB code are compared with the other computational methods. To investigate the effects of the stiffness and damping on the shafts and gears, different gear branch systems are considered. Some of the vibration results on the damped gear branched systems with viscous damper and structural damper are analyzed and discussed.
\end{abstract}

MSC 2010: 30, 34D99, $74 H 45$

Keywords: torsional vibration, gear branch system, damped system, undamped system

\section{Introduction}

In analysing the vibrations of continuous structures, identification and modelling of damping are of particular importance and complexity. This complexity has led to the analysis of structures either without damping or simple damping with approximations of real state [1]. A torsional vibration is a phenomenon that can cause the axial cutting to be in the centre of the rotary shaft due to the twisting of the centre, so this should be considered when designing the shaft. In marine vessels, the vibration in the shaft connecting the engine to the propeller is due to the inharmonious excitation resulting from these two parts. So, the study of the torsional vibration of the transmission shaft is vital for moving the ship. In the systems 
with torsional vibration, linear values with angular values are replaced in vibrational equations.

Many engineering vibration problems can be solved with the theory of a degree of freedom (DOF) system. Complex systems may have several DOF. The standard method for solving such systems, if the DOF is not more than three degrees, is to obtain the equations of motion by Newton's law of motion, the influence coefficient method, or by the Lagrange equations. Then differential equations of motion are solved by assuming an appropriate solution. If the DOF increases, solving differential equations of motion becomes more complicated for damped system [2]. Lin et al. showed that vibration propagation in complex ship structures at low frequencies can be attenuated by imposing irregularities to the ring frame locations in ships [3].

The natural frequency analysis for gear shaft systems is of practical importance and has a high sensitivity to the optimal design of these systems [4]. The torsional vibration in the marine power transmission system is usually very dangerous for the shaft line and the crankshaft [5]. So damping always exists in marine propulsion systems. Torsional damping may come from several sources, for example, shaft material, bearings, couplings, torsional vibration dampers, aerodynamic damper, etc. Shaft material or hysteretic dampers are due to the interaction of shaft material molecules, which leads to an increase in the material temperature of the shaft. A torsional vibration damper is a part that can be used in the connections between two-shaft cross-sections. The gear aerodynamic damping occurs due to interaction of the gear with the working fluid (such as steam, gas, air, etc.), lubricant, and coolant; which results in dissipation of the energy in the form of heat.

In other studies, the finite element method (FEM) has been used to solve the torsional vibration problems of direct and gear-branch systems [6]. Wu et al. have modelled the gearbox systems by elimination the twisting angles of the gears engaged decrease them to the direct equivalent system (or direct transmitted). Then, the overall mass matrix, damping matrix, stiffness matrix, and the torque vector were obtained from the direct transmitted system by the conventional FEM, and then obtained the natural frequencies and the mode shapes of the system [7]. For torsional vibration investigating of the crankshaft, it is assumed by 2-DOF and its stiffness is infinite. Also, due to insignificant influence, damping coefficients on the natural frequencies and the mode shapes of the devices were ignored from the damping coefficients matrix in solving the governing equations [8].

Drew et al. described two new test methods that were investigated for their suitability as methods of determining the torsional damping levels of the test gearbox of the back-to-back rig. The first test method investigated was to attempt a standard multi-input multi-output (MIMO) modal analysis of the gearbox test, in which the gearbox was used as a system with two inputs (torque per shaft) and the two output (angular velocity per shaft) was considered. The second test method was to assume the shape of a model for the test gearbox to match the calculation of the reacceptances for the gearbox and adjust the damping level in the model until it matched the experimental results [9]. 
Equipment failures due to torsional vibration are an important problem in the industry. Low torsional damping levels cause high stresses. Gearboxes are an important part of the marine power transmission system, so measuring the natural frequency of torsional vibration and investigate the effects of damping are of particular importance [10].

The effects of the stiffness and damping on both shafts and gears are important in multi-branch systems. Zou et al. employed a modal synthesis method for analysis the torsional vibration of the system. In this method, the system is divided into several subsystems and then solved by FEM [11]. Also, Ray presented a FEM of torsional vibration in geared shafts [12].

In research carried out by Murawski and Charchalis, the torsional vibration of the power transmission system was investigated by modelling the propeller, propeller shaft, middle shaft and main engine. In their research, numerical analysis was performed based on the FEM with experimental data measured by an experienced team, which was highly accurate and had an error rate of less than $6 \%$ [8].

Study of the ship propeller shaft vibrations is of particular importance. In this regard, the added mass and damping matrices of the propeller have an influence on the vibrational characteristics of the propulsion system. Mao and Young [13] have investigated the influence of the skew angle on the added mass and damping matrices, whose obtained results show that the increase in the Skew angle effects of the sway, heave, pitch and yaw components of the added mass and damping matrices, while the influence on the surge and roll components is negligible [13].

Aureli et al. modelled a rectangular thin cross section cantilever beam using the Euler-Bernoulli beam theory and investigated bending vibration in a high-viscosity fluid. The results of this study show that increasing the frequency and amplitude of the vibration causes vortex shedding and convection phenomena [14]. Firouzi and Ghassemi have recently presented the effect of variations in shaft diameter and torsional stiffness on the whirling speed of the ship propeller shafting system for systems that directly or indirectly attached the propeller to the engine [15]. Piatkowski used the algorithm phase-amplitude interpolation to create contours charts and estimate the shaft torsional vibrations and transient operating conditions of rotary machines [16].

The following sections are organized as follows. Governing equations are described in Section 2. Validation is given in Section 3. Vibration analysis of the damped gear branched system are presented in Section 4, and Section 5 is given for the conclusions.

\section{Governing equations}

Power transmission systems have many elements such as shaft, gearbox, coupling, bearings and stern tube between the engine to the propeller. Their tasks are to deliver the power from the engine to the propeller to provide forward speed to the ship. Here, we consider a gear branched system as shown in Figure 1. It has 
two shafts and 4 gears with stiffness and damping. All of the consideration parameters define the mass momentum of inertia of the shafts $I_{p}$ and $I_{q}$, the mass momentum of inertia of the gears $I_{i}(i=1-4)$, the damping of each gear $C_{i}(i=1-4)$, torsional dampers of different segments of the shaft $C_{p}$ and $C_{q}$, and torsional stiffness of shafts $k_{p}$ and $k_{q}$.

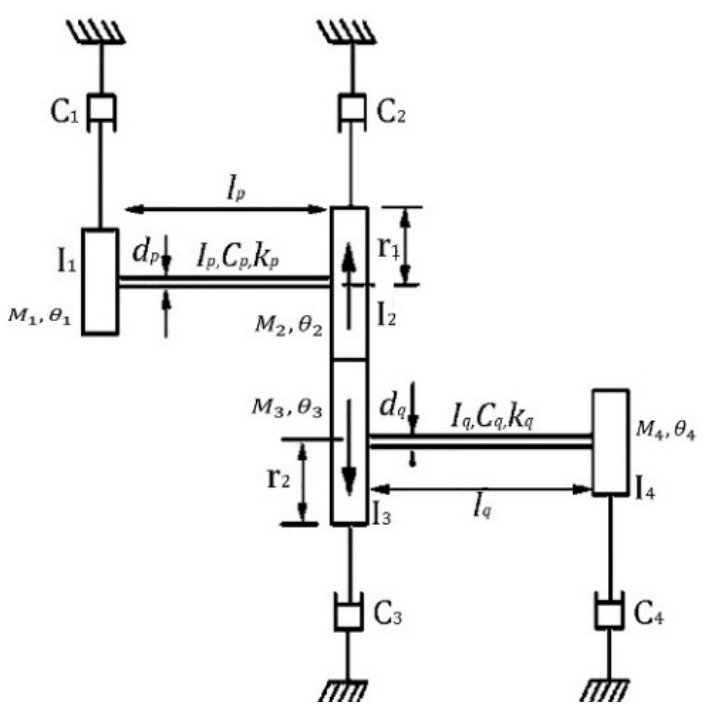

Fig. 1. Gear branched system

We write the vibrational equations of the above system as follows:

$$
\begin{aligned}
& \left(\mathrm{I}_{1}+\frac{1}{3} \mathrm{I}_{\mathrm{P}}\right) \ddot{\theta}_{1}+\frac{1}{6} \mathrm{I}_{\mathrm{P}} \ddot{\theta}_{2}+\left(\mathrm{C}_{1}+\mathrm{C}_{\mathrm{P}}\right) \dot{\theta}_{1}-\mathrm{C}_{\mathrm{P}} \dot{\theta}_{2}+\mathrm{k}_{\mathrm{P}}\left(\theta_{1}-\theta_{2}\right)=\mathrm{M}_{1} \\
& \frac{1}{6} \mathrm{I}_{\mathrm{P}} \ddot{\theta}_{1}+\left(\mathrm{I}_{2}+\frac{1}{3} \mathrm{I}_{\mathrm{P}}\right) \ddot{\theta}_{2}-\mathrm{C}_{\mathrm{P}} \dot{\theta}_{1}+\left(\mathrm{C}_{2}+\mathrm{C}_{\mathrm{P}}\right) \dot{\theta}_{2}-\mathrm{k}_{\mathrm{P}}\left(\theta_{1}-\theta_{2}\right)=\mathrm{M}_{2} \\
& \left(\mathrm{I}_{3}+\frac{1}{3} \mathrm{I}_{\mathrm{q}}\right) \ddot{\theta}_{3}+\frac{1}{6} \mathrm{I}_{\mathrm{q}} \ddot{\theta}_{4}+\left(\mathrm{C}_{3}+\mathrm{C}_{\mathrm{q}}\right) \dot{\theta}_{3}-\mathrm{C}_{\mathrm{q}} \dot{\theta}_{4}+\mathrm{k}_{\mathrm{q}}\left(\theta_{3}-\theta_{4}\right)=\mathrm{M}_{3} \\
& \frac{1}{6} \mathrm{I}_{\mathrm{q}} \ddot{\theta}_{3}+\left(\mathrm{I}_{4}+\frac{1}{3} \mathrm{I}_{\mathrm{q}}\right) \ddot{\theta}_{4}-\mathrm{C}_{\mathrm{q}} \dot{\theta}_{3}+\left(\mathrm{C}_{4}+\mathrm{C}_{\mathrm{q}}\right) \dot{\theta}_{4}-\mathrm{k}_{\mathrm{q}}\left(\theta_{3}-\theta_{4}\right)=\mathrm{M}_{4}
\end{aligned}
$$

Then for each shaft we write the above equations in matrix form.

$$
\left[\begin{array}{cc}
\mathrm{I}_{1}+\frac{1}{3} \mathrm{I}_{\mathrm{P}} & \frac{1}{6} \mathrm{I}_{\mathrm{P}} \\
\frac{1}{6} \mathrm{I}_{\mathrm{P}} & \mathrm{I}_{2}+\frac{1}{3} \mathrm{I}_{\mathrm{P}}
\end{array}\right]\left\{\begin{array}{l}
\ddot{\theta}_{1} \\
\ddot{\theta}_{2}
\end{array}\right\}+\left[\begin{array}{cc}
\mathrm{C}_{1}+\mathrm{C}_{\mathrm{P}} & -\mathrm{C}_{\mathrm{P}} \\
-\mathrm{C}_{\mathrm{P}} & \mathrm{C}_{2}+\mathrm{C}_{\mathrm{P}}
\end{array}\right]\left\{\begin{array}{l}
\dot{\theta}_{1} \\
\dot{\theta}_{2}
\end{array}\right\}+\left[\begin{array}{cc}
\mathrm{k}_{\mathrm{P}} & -\mathrm{k}_{\mathrm{P}} \\
-\mathrm{k}_{\mathrm{P}} & \mathrm{k}_{\mathrm{P}}
\end{array}\right]\left\{\begin{array}{l}
\theta_{1} \\
\theta_{2}
\end{array}\right\}=\left\{\begin{array}{l}
\mathrm{M}_{1} \\
\mathrm{M}_{2}
\end{array}\right\}
$$


$\left[\begin{array}{cc}\mathrm{I}_{3}+\frac{1}{3} \mathrm{I}_{\mathrm{q}} & \frac{1}{6} \mathrm{I}_{\mathrm{q}} \\ \frac{1}{6} \mathrm{I}_{\mathrm{q}} & \mathrm{I}_{4}+\frac{1}{3} \mathrm{I}_{\mathrm{q}}\end{array}\right]\left\{\begin{array}{l}\ddot{\theta}_{3} \\ \ddot{\theta}_{4}\end{array}\right\}+\left[\begin{array}{cc}\mathrm{C}_{3}+\mathrm{C}_{\mathrm{q}} & -\mathrm{C}_{\mathrm{q}} \\ -\mathrm{C}_{\mathrm{q}} & \mathrm{C}_{4}+\mathrm{C}_{\mathrm{q}}\end{array}\right]\left\{\begin{array}{c}\dot{\theta}_{3} \\ \dot{\theta}_{4}\end{array}\right\}+\left[\begin{array}{cc}\mathrm{k}_{\mathrm{q}} & -\mathrm{k}_{\mathrm{q}} \\ -\mathrm{k}_{\mathrm{q}} & \mathrm{k}_{\mathrm{q}}\end{array}\right]\left\{\begin{array}{l}\theta_{3} \\ \theta_{4}\end{array}\right\}=\left\{\begin{array}{l}\mathrm{M}_{3} \\ \mathrm{M}_{4}\end{array}\right\}$

where: $I_{P}=\rho\left(\pi d^{4} / 32\right) l_{P}$ and $k_{P}=G\left(\pi d^{4} / 32\right) / l_{P}$ the mass moment of inertia and torsional stiffness of the shaft $p$, respectively, also for shafts $q$ the mass moment of the inertia and torsional stiffness of the shaft are obtained.

Using the ratio between gears 2 and 3:

$$
r_{2} \theta_{2}=-r_{3} \theta_{3}, \quad \theta_{3}=-\frac{r_{2}}{r_{3}} \theta_{2}=-R \theta_{2}, \quad R=\frac{r_{2}}{r_{3}}
$$

The negative sign $R$ is due to the opposite direction $\theta_{3}$ to $\theta_{2}$. Since $r_{2}$ and $r_{3}$ are the radius of the gears 2 and 3, respectively. $R$ is the gear ratio. Relations between the shafts $q$ and $p$ with considering the gear ratio, the following equations are defined:

$$
\{\dot{\theta}\}=[\lambda]\{\theta\},\{\dot{\theta}\}=\left\{\theta_{3}, \theta_{4}\right\},\{\theta\}=\left\{\theta_{2}, \theta_{4}\right\},[\lambda]=\left[\begin{array}{cc}
-\mathrm{R} & 0 \\
0 & 1
\end{array}\right]
$$

By derivation of equation (8) we have:

$$
\{\dot{\theta}\}=[\lambda]\{\dot{\theta}\},\{\ddot{\theta}\}=[\lambda]\{\ddot{\theta}\}
$$

where:

$$
\{\dot{\theta}\}=\left\{\dot{\theta}_{3}, \dot{\theta}_{4}\right\},\{\dot{\theta}\}=\left\{\dot{\theta}_{2} \cdot \dot{\theta}_{4}\right\},\{\ddot{\theta}\}=\left\{\ddot{\theta}_{3}, \ddot{\theta}_{4}\right\},\{\ddot{\theta}\}=\left\{\ddot{\theta}_{2} \cdot \ddot{\theta}_{4}\right\}
$$

In the above equations, $\{$,$\} represents the vector of the column and [\lambda]$ represents the transformation matrix to remove the dependence of the angular displacement $\theta_{3}$. By replacing the equations (8), (9) in equation (6) and multiplying the two sides of the resulting equation in $[\lambda]^{T}$ we will have:

$$
\begin{gathered}
{\left[\mathrm{m}_{\mathrm{e}}\right]\{\ddot{\theta}\}+\left[\mathrm{C}_{\mathrm{e}}\right]\{\dot{\theta}\}+\left[\mathrm{k}_{\mathrm{e}}\right]\{\theta\}=\left\{\mathrm{M}_{\mathrm{e}}\right\}} \\
{\left[\mathrm{m}_{\mathrm{e}}\right]=\left[\begin{array}{cc}
\mathrm{R}^{2}\left(\mathrm{I}_{3}+\frac{1}{3} \mathrm{I}_{\mathrm{q}}\right) & -\mathrm{R}\left(\frac{1}{6} \mathrm{I}_{\mathrm{q}}\right) \\
-\mathrm{R}\left(\frac{1}{6} \mathrm{I}_{\mathrm{q}}\right) & \mathrm{I}_{4}+\frac{1}{3} \mathrm{I}_{\mathrm{q}}
\end{array}\right], \quad\left[\mathrm{C}_{\mathrm{e}}\right]=\left[\begin{array}{cc}
\mathrm{R}^{2}\left(\mathrm{C}_{3}+\mathrm{C}_{\mathrm{q}}\right) & \mathrm{RC}_{\mathrm{q}} \\
\mathrm{RC}_{\mathrm{q}} & \mathrm{C}_{4}+\mathrm{C}_{\mathrm{q}}
\end{array}\right],} \\
{\left[\mathrm{k}_{\mathrm{e}}\right]=\left[\begin{array}{cc}
\mathrm{R}^{2} \mathrm{k}_{\mathrm{q}} & \mathrm{Rk}_{\mathrm{q}} \\
\mathrm{Rk}_{\mathrm{q}} & \mathrm{k}_{\mathrm{q}}
\end{array}\right], \quad\left\{\mathrm{f}_{\mathrm{e}}\right\}=\left\{\begin{array}{c}
-\mathrm{RM}_{3} \\
\mathrm{M}_{4}
\end{array}\right\}}
\end{gathered}
$$

Thus, the mass matrix $\left[m_{e}\right]$, the damping matrix $\left[C_{e}\right]$, the hard matrix $\left[k_{e}\right]$ and the load vector $\left\{M_{e}\right\}$ of the drive shaft $\mathrm{q}$ are defined by equations (12). If $R=-1$, 
similar relations are obtained for the drive shaft $p$ (according to equation (1)). In other words, the equation (12) is the key word of the method.

$$
\begin{gathered}
\left.\left.\left[\begin{array}{ccc}
\mathrm{I}_{1}+\frac{1}{3} \mathrm{I}_{\mathrm{P}} & \frac{1}{6} \mathrm{I}_{\mathrm{P}} & 0 \\
\frac{1}{6} \mathrm{I}_{\mathrm{P}} & \left(\mathrm{I}_{2}+\frac{1}{3} \mathrm{I}_{\mathrm{P}}\right)+\mathrm{R}^{2}\left(\mathrm{I}_{3}+\frac{1}{3} \mathrm{I}_{\mathrm{q}}\right) & -\mathrm{R}\left(\frac{1}{6} \mathrm{I}_{\mathrm{q}}\right) \\
0 & -\mathrm{R}\left(\frac{1}{6} \mathrm{I}_{\mathrm{q}}\right) & \mathrm{I}_{4}+\frac{1}{3} \mathrm{I}_{\mathrm{q}}
\end{array}\right]\right\} \begin{array}{c}
\ddot{\theta}_{1} \\
\ddot{\theta}_{2} \\
\ddot{\theta}_{4}
\end{array}\right\} \\
+\left[\begin{array}{ccc}
\mathrm{C}_{1}+\mathrm{C}_{\mathrm{P}} & -\mathrm{C}_{\mathrm{P}} & 0 \\
-\mathrm{C}_{\mathrm{P}} & \left(\mathrm{C}_{2}+\mathrm{C}_{\mathrm{P}}\right)+\mathrm{R}^{2}\left(\mathrm{C}_{3}+\mathrm{C}_{\mathrm{q}}\right) & \mathrm{RC}_{\mathrm{q}} \\
0 & \mathrm{RC}_{\mathrm{q}} & \mathrm{C}_{4}+\mathrm{C}_{\mathrm{q}}
\end{array}\right]\left\{\begin{array}{c}
\dot{\theta}_{1} \\
\dot{\theta}_{2} \\
\dot{\theta}_{4}
\end{array}\right\} \\
+\left[\begin{array}{ccc}
\mathrm{k}_{\mathrm{P}} & -\mathrm{k}_{\mathrm{P}} & 0 \\
-\mathrm{k}_{\mathrm{P}} & \mathrm{k}_{\mathrm{P}}+\mathrm{R}^{2} \mathrm{k}_{\mathrm{q}} & \mathrm{Rk}_{\mathrm{q}} \\
0 & \mathrm{Rk}_{\mathrm{q}} & \mathrm{k}_{\mathrm{q}}
\end{array}\right]\left\{\begin{array}{l}
\theta_{1} \\
\theta_{2} \\
\theta_{4}
\end{array}\right\}=\left\{\begin{array}{c}
\mathrm{M}_{1} \\
\mathrm{M}_{2}-\mathrm{RM}_{3} \\
\mathrm{M}_{4}
\end{array}\right\}
\end{gathered}
$$

\section{Validation}

In this work, the governing equations of the torsional vibration of the multibranch gears system are derived and free vibration is considered. Overall mass, damping and torsional stiffness matrices were obtained, and a MATLAB code was used for solving and obtaining natural frequencies of the system. To verify the results, the system shown in Figure 2 was considered. Our results were compared with the results shown in Table 2, and they were in good conformity.

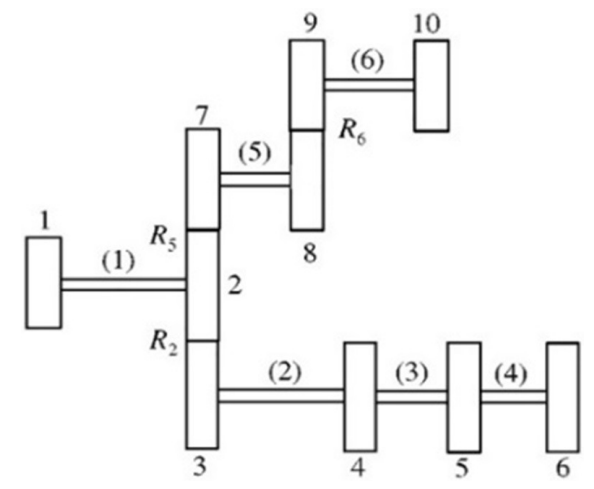

Fig. 2. The original three-branched gear system

For the original three-branched gear system, shown in Figure 2, the main dimensions and physical properties of the gears and shafts are presented in Table 1.

In fact, the given data, the mass moment of inertia for the gears, $I_{j}(j=1-10)$ and the torsional stiffness of the shafts $k_{i}(i=1-6)$ are shown in Table 1. Also, 
other data such as the diameter of the gears $D_{j}$, the diameter of the shaft $d_{i}$, and the length of the shaft $l_{i}$ are given in this table. For gears and shafts $\rho=20.2063 \mathrm{~kg} / \mathrm{m}^{3}$ and $\mathrm{G}=79.29 \cdot 10^{9} \mathrm{~N} / \mathrm{m}^{2}, R_{2}=\frac{D_{2}}{D_{3}}=2.318, R_{5}=\frac{D_{2}}{D_{7}}=4.8182$ and $R_{6}=\frac{D_{8}}{D_{9}}=8.4906$ is gear ratio.

Table 1

Main dimensions and physical properties of shafts and gears

\begin{tabular}{|c|c|c|c|c|c|c|}
\hline \multicolumn{3}{|c|}{ Gear } & \multicolumn{3}{c|}{ Shaft } \\
\hline $\begin{array}{c}\text { No. } \\
j\end{array}$ & $\begin{array}{c}\text { Mass moments } \\
\text { of inertia } \\
I_{j}\left[\mathrm{~kg} \cdot \mathrm{m}^{2}\right]\end{array}$ & $\begin{array}{c}\text { Diameters } D_{j} \\
{[\mathrm{~m}]}\end{array}$ & $\begin{array}{c}\text { No. } \\
i\end{array}$ & $\begin{array}{c}\text { Torsional stiffness } \\
k_{i} \times 10^{6}[\mathrm{~N} \cdot \mathrm{m} / \mathrm{rad}]\end{array}$ & $\begin{array}{c}\text { Diameters } \\
D_{i}[\mathrm{~m}]\end{array}$ & $\begin{array}{c}\text { Lengths } \\
l_{i}[\mathrm{~m}]\end{array}$ \\
\hline 1 & 1098.213 & 1.69 & 1 & 0.6169 & 0.127 & 3.283 \\
\hline 2 & 111.448 & 1.3 & 2 & 0.1966 & 0.102 & 4.219 \\
\hline 3 & 4.067 & 0.56 & 3 & 3.9861 & 0.102 & 0.208 \\
\hline 4 & 45.985 & 1.039 & 4 & 7.7621 & 0.102 & 0.107 \\
\hline 5 & 26.438 & 0.908 & 5 & 0.2192 & 0.102 & 3.784 \\
\hline 6 & 26.438 & 0.908 & 6 & 0.2429 & 0.064 & 0.521 \\
\hline 7 & 0.407 & 0.27 & & & & \\
\hline 8 & 33.895 & 1.2192 & & & & \\
\hline 9 & 0.0407 & 1.431 & & & & \\
\hline 10 & 9.2196 & 0.698 & & & & \\
\hline
\end{tabular}

The natural frequencies of the torsional vibration of the above system are presented in the following table in two states with/without of the shafts mass. The first frequency obtained is zero $\left(\omega_{0}=0\right)$ and other natural frequencies are given and compared in Table 2.

Table 2

Several of the lowest natural frequencies of the original three-branched gear system

\begin{tabular}{|l|c|c|c|c|c|c|}
\hline & $\omega_{1}$ & $\omega_{2}$ & $\omega_{3}$ & $\omega_{4}$ & $\omega_{5}$ & Shaft mass \\
\hline \multirow{2}{*}{ Present method } & 23.087 & 41.2902 & 215.2224 & 376.6524 & 710.4798 & considered \\
\cline { 2 - 7 } & 23.089 & 41.3231 & 217.6014 & 376.9155 & 712.6998 & neglected \\
\hline \multirow{2}{*}{ FEM [2] } & 23.087 & 41.2902 & 215.2224 & 376.6524 & 710.4786 & considered \\
\cline { 2 - 7 } & 23.089 & 41.3228 & 217.6013 & 376.9155 & 712.6985 & neglected \\
\hline FEM [10] & 23.089 & 41.3228 & 217.6013 & 376.9155 & 712.6985 & neglected \\
\hline Holzer [9] & 23.092 & 41.3290 & 217.9722 & 376.9155 & 713.3585 & neglected \\
\hline
\end{tabular}




\section{Vibration analysis of the damped gear branched system}

This example is given for vibration analysis of the damped gear branched system. It includes stiffness on the shaft and damping on both shafts and gears in two states as shown in Figure 3.

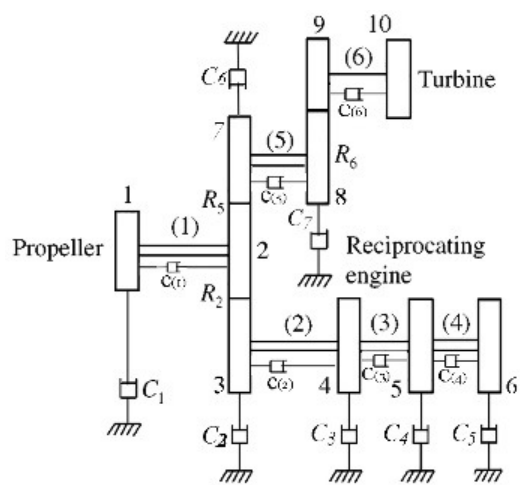

Fig. 3. The three-branched gear system with viscous damper and with structural damper

\subsection{Vibration analysis of a damped gear branched system with viscous damper}

We consider the analysis of the damped gear branched system with the damper between the gears and fluid, as shown in Figure 3. In this case, the structural damper is equal to zero $C_{(i)}(i=1-6)=0$.

The damping coefficients for the seven dampers shown in the figure above, $C_{j}(j=1-7)$, were assumed to be the same. We study the influence of damping with consideration of the mass of all shafts for different cases $C_{1}=9-11.7 \mathrm{Nms} / \mathrm{rad}$ and $C_{j}(j=2-7)=100-130 \mathrm{Nms} / \mathrm{rad}$. The real part $\left(\omega_{R r}\right)$ of the special values of $\left(\alpha_{r} \cdot r=1-6\right)$ is related to the damping parameter and the imaginary part $\left(\omega_{I r}\right)$ to the damping natural frequencies, whose values are shown in Table 3.

Table 3

Influence of damping on the natural frequencies of the damped gear branched system with the viscous damper

\begin{tabular}{|c|c|c|c|c|c|c|c|}
\hline \multirow{2}{*}{$\begin{array}{c}\text { Damping coefficient } \\
C_{j}(j=1-7) \\
{[\mathrm{N} \cdot \mathrm{m} \cdot \mathrm{s} / \mathrm{rad}]}\end{array}$} & \multicolumn{7}{|c|}{ Eigenvalues $\alpha_{r}=\bar{\omega}_{R r}+i \bar{\omega}_{I r}$} \\
\hline & $\alpha_{1}$ & $\alpha_{2}$ & $\alpha_{3}$ & $\alpha_{4}$ & $\alpha_{5}$ & $\alpha_{6}$ & Remarks \\
\hline$C_{j}$ & $\begin{array}{c}0.01 \\
23.08 \\
\end{array}$ & $\begin{array}{c}1.52 \\
41.29 \\
\end{array}$ & $\begin{array}{c}9.87 \\
217.36 \\
\end{array}$ & $\begin{array}{c}1.49 \\
376.91 \\
\end{array}$ & $\begin{array}{c}1.30 \\
712.69 \\
\end{array}$ & $\begin{array}{c}1.87 \\
828.36 \\
\end{array}$ & $\begin{array}{l}\omega_{R r} \\
\omega_{I r}\end{array}$ \\
\hline $1.1 C_{j}$ & $\begin{array}{c}0.02 \\
23.08 \\
\end{array}$ & \begin{tabular}{|c|}
1.68 \\
41.28 \\
\end{tabular} & $\begin{array}{c}10.86 \\
217.31 \\
\end{array}$ & $\begin{array}{c}1.64 \\
376.91 \\
\end{array}$ & $\begin{array}{c}1.43 \\
712.69 \\
\end{array}$ & $\begin{array}{c}2.06 \\
828.36 \\
\end{array}$ & $\begin{array}{l}\omega_{R r} \\
\omega_{I r} \\
\end{array}$ \\
\hline $1.2 C_{j}$ & $\begin{array}{c}0.02 \\
23.08 \\
\end{array}$ & $\begin{array}{c}1.83 \\
41.28 \\
\end{array}$ & $\begin{array}{c}11.85 \\
217.26 \\
\end{array}$ & $\begin{array}{c}1.79 \\
376.91 \\
\end{array}$ & $\begin{array}{c}1.56 \\
712.69 \\
\end{array}$ & $\begin{array}{c}2.25 \\
828.36 \\
\end{array}$ & $\begin{array}{l}\omega_{R r} \\
\omega_{I r} \\
\end{array}$ \\
\hline $1.3 C_{j}$ & $\begin{array}{c}0.02 \\
23.08 \\
\end{array}$ & $\begin{array}{c}1.98 \\
41.27 \\
\end{array}$ & $\begin{array}{c}12.84 \\
217.20 \\
\end{array}$ & $\begin{array}{c}1.93 \\
376.91 \\
\end{array}$ & $\begin{array}{c}1.69 \\
712.69 \\
\end{array}$ & $\begin{array}{c}2.43 \\
828.36 \\
\end{array}$ & $\begin{array}{l}\omega_{R r} \\
\omega_{I r} \\
\end{array}$ \\
\hline
\end{tabular}


As shown in Table 3, we increase the value of $C_{j}$ in the three steps by adding $10 \%$ at each step. By increasing the value of $C_{j}$, the natural frequency values of the damping $\left(\omega_{R r}\right)$ slightly increase while $\left(\omega_{I r}\right)$ does not almost change.
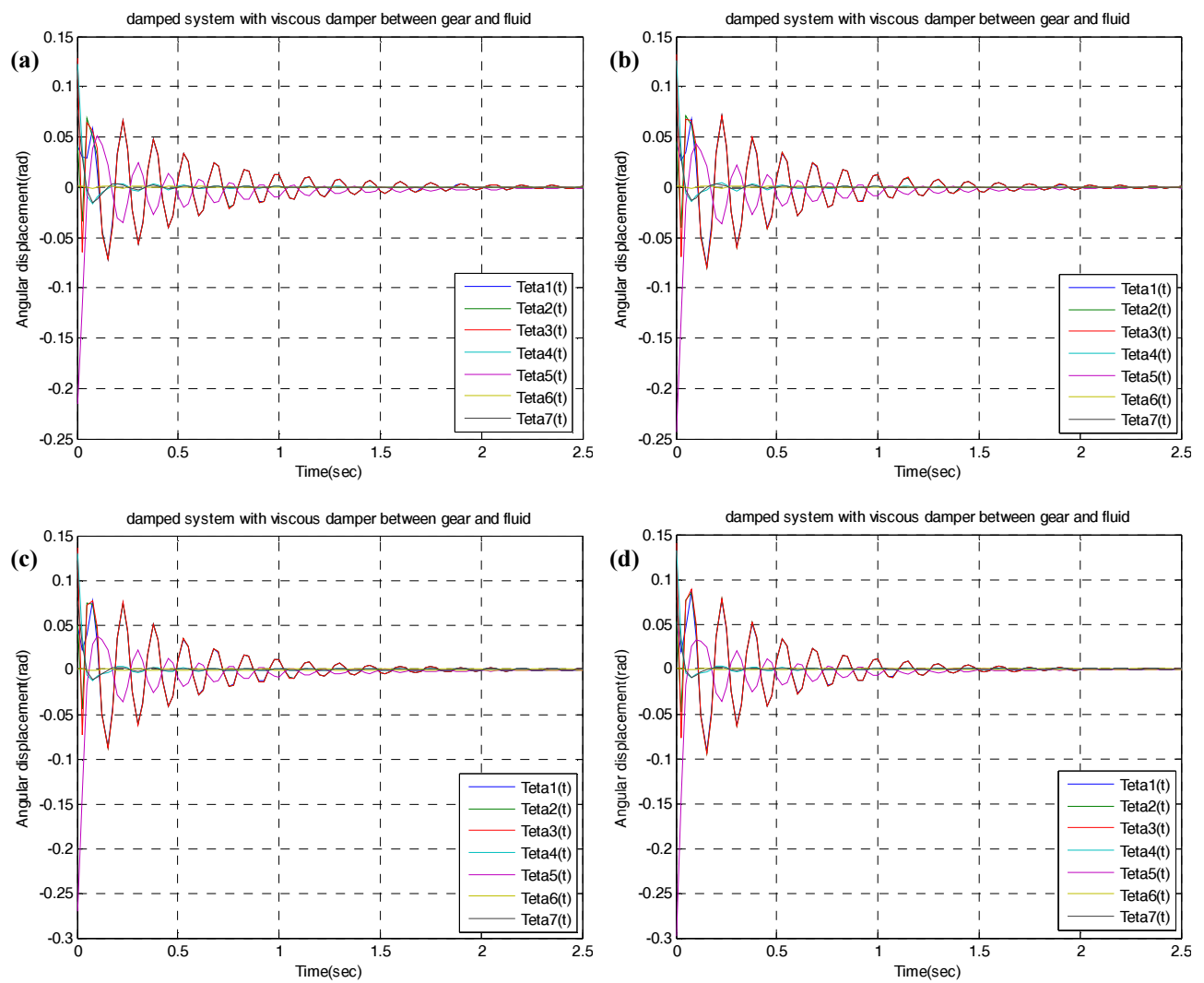

Fig. 4. Damped system with viscous damper between gears and fluid (a) for $C_{j}(\mathrm{~b})$ for $1.1 C_{j}(\mathrm{c})$ for $1.2 C_{j}(\mathrm{~d})$ for $1.3 C_{j}$

In Figure 4, by increasing the amount of damping coefficient $C_{j}$, the torsional vibration amplitude increases at initial times and the torsional vibration in $\theta_{3}$ and $\theta_{5}$ will be damped later than the other parts. By increasing the amount of damping coefficient $C_{j}$, the duration of the damping is also reduced.

\subsection{Vibration analysis of a damped gear branched system with viscous damper and structural damper}

We consider Figure 3 for analysis of the damped gear branched system with the viscous damper and structural damper. In this case, consider the values of $C_{j}$ as before and consider the structural damping coefficients for shafts equal to 
$C_{(i)},(i=1-6)=150-195 \mathrm{Nms} / \mathrm{rad}$. The values obtained for the damping natural frequency $\left(\omega_{I r}\right)$ and the damping parameter $\left(\omega_{R r}\right)$ are given in Table 4.

Table 4

Influence of damping on the natural frequencies of the damped gear branched system with viscous damper and with structural damper

\begin{tabular}{|c|c|c|c|c|c|c|c|}
\hline Damping coefficient & \multicolumn{7}{|c|}{ Eigenvalues $\alpha_{r}=\bar{\omega}_{R r}+i \bar{\omega}_{I r}$} \\
$C_{(i)}(i=1-6)$ & \multicolumn{7}{|c|}{${ }(j=1-7)$} \\
\cline { 2 - 8 }$\left[\begin{array}{c}C_{j}(j \cdot \mathrm{m} \cdot \mathrm{s} / \mathrm{rad}] \\
\right.$\cline { 2 - 8 }\end{array} & $\alpha_{1}$ & $\alpha_{2}$ & $\alpha_{3}$ & $\alpha_{4}$ & $\alpha_{5}$ & $\alpha_{6}$ & Remarks \\
\hline$C_{(i)}, C_{j}$ & 0.09 & 2.16 & 25.62 & 4.97 & 161.48 & 9.84 & $\omega_{R r}$ \\
& 23.08 & 41.26 & 216.10 & 376.83 & 694.16 & 828.30 & $\omega_{I r}$ \\
\hline \multirow{2}{*}{$1.1 C_{(i)}, 1.1 C_{j}$} & 0.10 & 2.36 & 27.85 & 5.40 & 174.17 & 10.65 & $\omega_{R r}$ \\
& 23.08 & 41.25 & 215.83 & 376.9182 & 691.08 & 828.29 & $\omega_{I r}$ \\
\hline \multirow{2}{*}{$1.2 C_{(i)}, 1.2 C_{j}$} & 0.11 & 2.58 & 30.38 & 5.88 & 190.00 & 11.26 & $\omega_{R r}$ \\
& 23.08 & 41.23 & 215.49 & 376.80 & 686.90 & 828.27 & $\omega_{I r}$ \\
\hline \multirow{2}{*}{$1.3 C_{(i)}, 1.3 C_{j}$} & 0.12 & 2.79 & 32.92 & 6.37 & 205.84 & 12.58 & $\omega_{R r}$ \\
\hline
\end{tabular}
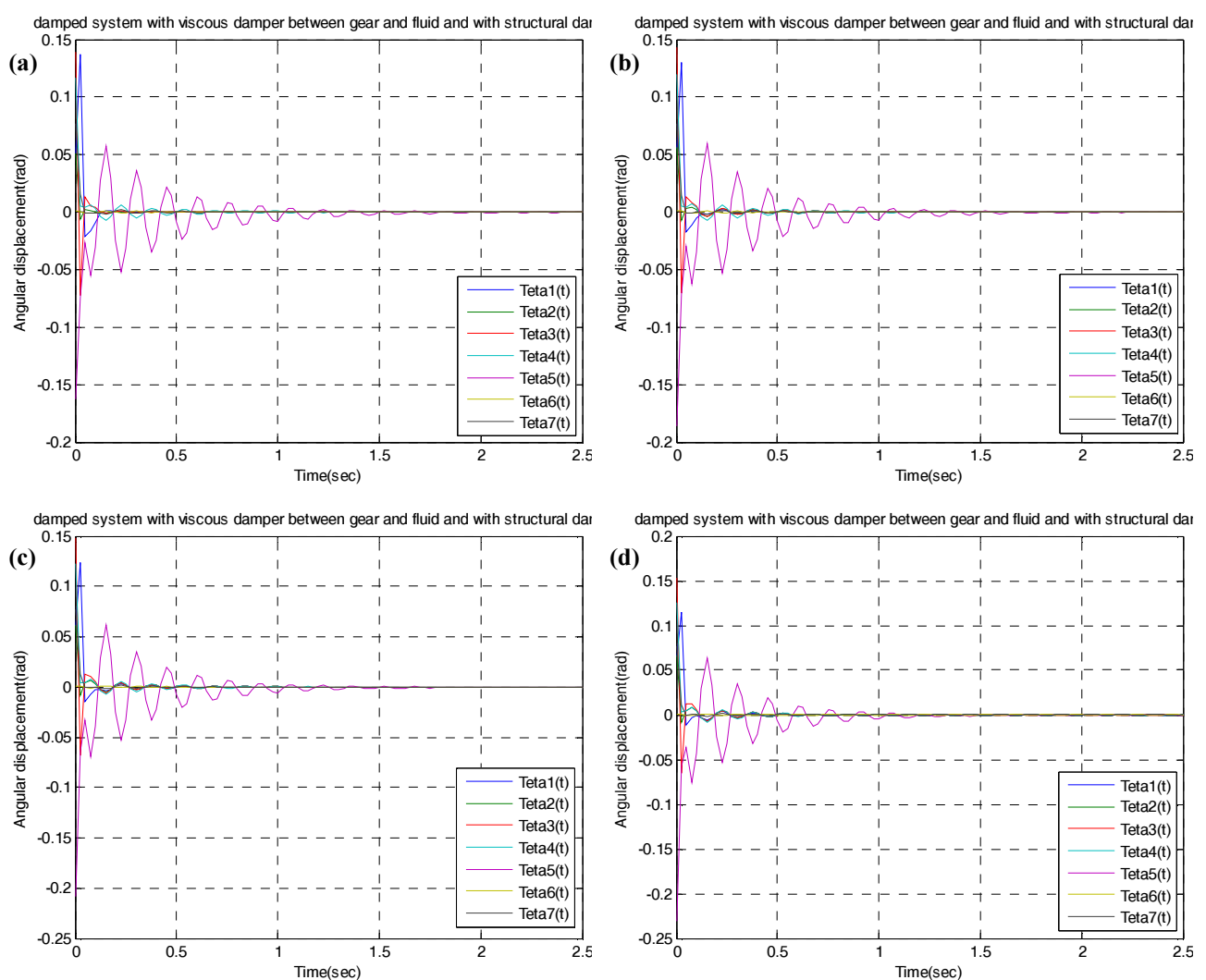

Fig. 5. Damped system with viscous damper and with structural damper (a) for $C_{(i)}$,

(b) for $1.1 C_{(i)}, 1.1 C_{j}(\mathrm{c})$ for $1.2 C_{(i)}, 1.2 C_{j}(\mathrm{~d})$ for $1.3 C_{(i)}$ 
In Table 4, we increase the amount of $C_{(i)}$ and $C_{j}$ in the three steps at each step by the amount of $10 \%$. By increasing these values, the damping natural frequency $\left(\omega_{I r}\right)$, other than for $\alpha_{1}$, is not significantly reduced in the other cases, but in all cases the values of the damping parameter $\left(\omega_{R r}\right)$ increase. In Figure 5, increasing the amount of damping coefficient $C_{(i)}$ and $C_{j}$, the torsional vibration amplitude increases at initial times and torsional vibration at $\theta_{5}$ will be damped later than other parts. As the number of damping coefficients increases, the duration of the damping also decreases.

\section{Conclusions}

The effect of the damping coefficients has been achieved to estimate the torsional vibration of the multi-branch gears systems. Based on the presented computational results, the following conclusions are drawn:

1. Increased damping leads to an increase in the torsional vibration amplitude in the initial times, and this issue is very important in the vibration and should increase the damping coefficient, especially in different parts of the engine for any reason (oil reduction, erosion, etc.) is prevented.

2. With a structural damper applied to the shafts and the gears, the torsional vibration amplitude is lower than that for which only the viscous damper was considered.

3. Increased damping, in particular structural damping, leads to a reduction in the damping time of the vibration amplitude, but, on the other hand, causes energy dissipation.

It is our spirit to investigate on the stiffness of gearwheel teeth in near future. In this regard, all dynamics equations are required to be obtained. The MATLAB code should be improved and employed with new examples of the stiffness effect of the gearteeth.

\section{References}

[1] Wilson W.K., Practical Solution of Torsional Vibration Problems, 3rd edition, Vol 1\&2, Chapman \& Hall, London 1956 and 1963.

[2] Mohta Brijgopal R., Evaluation of methods for analysis of multi-degree-of-freedom systems with damping, Masters Theses, 5272, 1968.

[3] Lin T.R., Pan J., O'Shea P.J., Mechefske Ch.K., A study of vibration and vibration control of ship structures, Marine Structures 2009, 22, 730-743.

[4] Liu Z.S., Chen S.H., Derivatives of eigenvalues for torsional vibration of geared shaft systems, Journal of Vibration and Acoustics 1993, 115, 277-279.

[5] Brydum L., Jakobsen S.B., Vibration characteristics of two-stroke, low speed diesel engines, MAN B\&W Diesel, Copenhagen 1987, 1-16.

[6] Kushwaha V., Analysis of torsional vibration characteristics for multi-rotor and gear-branched systems using FEM, National Institute of Technology, Rourkela 2012, 4, 39-41. 
[7] Wu J.S., Chen C.H., Torsional vibration analysis of gear-branched systems by finite element method, Journal of Sound and Vibration 2001, 240(1), 159-182.

[8] Murawski L., Charchalis A., Review simplified method of torsional vibration calculation of marine power transmission system, Marine Structures 2014, 39, 335-349.

[9] Drew S.J., Stone B.J., Torsional damping measurements for a gearbox, Mechanical Systems and Signal Processing 2005, 19, 1096-1106.

[10] Drew S.J., Stone B.J., Torsional damping of a back-to-back gearbox rig, Proc. Instn. Mech. Engrs. 2002, 216 Part K, 157-168.

[11] Zou CH.P., Chen D.Sh., Hua H.X., Torsional vibration analysis of complicated multi-branched shafting systems by MSM, Journal of Vibration and Acoustics 2003, 125, 317-323.

[12] Ray D., A Study on FEA of Torsional Vibration in Geared Shafts, National Institute of Technology, Rourkela 2010, 2, 25-27.

[13] Mao Y., Young Y.L., Influence of skew on the added mass and damping characteristics of marine propellers, Ocean Engineering 2016, 121, 437-452.

[14] Aureli M., Basaran M.E., Porfiri M., Nonlinear finite amplitude vibrations of sharp-edged beams in viscous fluids, Journal of Sound and Vibration 2012, 331, 1624-1654.

[15] Firouzi J., Ghassemi H., The effect of the shaft diameter and torsional stiffness on the whirling speed of the ship propeller shafting system, Journal of Mechanical Design and Vibration 2017, $5,37-42$.

[16] Piatkowski J., The visualization of shaft vibration using the algorithm of phase-amplitude data interpolation, Journal of Applied Mathematics and Computational Mechanics 2016, 15(1), 137-148. 